\title{
Recycling the Magnesium Alloy AZ91D in Solid State
}

\author{
Jian-Yih Wang ${ }^{1}$, Ying-Nan Lin ${ }^{2}$, Tien-Chan Chang ${ }^{2}$ and Shyong Lee ${ }^{2}$ \\ ${ }^{1}$ Department of Materials Science and Engineering, National Dong Hwa University, \\ No. 1, Sec. 2, Da-Hsueh Rd., Shoufeng, Hualien County 97401, Taiwan, R. O. China \\ ${ }^{2}$ Department of Mechanical Engineering, National Central University, \\ No. 300, Jhongda Rd., Jhongli City, Taoyuan County 32001, Taiwan, R. O. China
}

The commonly used die-cast magnesium alloy AZ91D in chip form bearing different environmental corrosive conditions was compacted, and then extruded in order to assess the feasibility of recycling in solid-state. This recycled material showed no inferior mechanical properties than its un-chipped counterpart. It was also aging hardenable just as the original bulk material. Metallurgical investigation of the processed material showed a eutectic-like microstructure in the specimens receiving solution treatment followed by aging. This phenomenon is considered as the same as isothermal transformation in the eutectoid steel.

(Received October 18, 2005; Accepted December 16, 2005; Published April 15, 2006)

Keywords: AZ91D magnesium alloy, solid state recycling, aging, lamellar structure

\section{Introduction}

Use of magnesium alloys, mainly for vehicle parts as well as electronic appliances, has been booming in recent years because of their lightweight compared to aluminum alloys and good creep resistance relative to plastics. ${ }^{1,2)}$ Accompanying this consumption increase, scrap from manufacturing and product replacement create a big amount of waste which needs recycled. In general, metallic scraps always can be remelted to cast into ingot for subsequent processing. However, this liquid state recycling may not be efficient for magnesium alloys because of the needs of special protective environment and extra caution. ${ }^{3)}$ So, solid state recycling becomes highly desirable, and a straightforward method for recycling solid material is to chop up the scrap residue or chip the bulk, then compact and extrude it. Although there are seemingly limited researches using this route, ${ }^{4-10)}$ we do not only assess the feasibility of recycling magnesium alloys in solid state but also expect a distinctive feature. That is, the surface layer of oxidized or corroded chips may peel off and break up to form hard and dispersed particles to strengthen matrix. The critical engineering consideration should be good mechanical properties after extruding; that is, the recycled material needs to possess comparable strength and ductility as those from the typical die cast and/or extruded. Here, the AZ91D was selected as the experimental material because it is the most commonly used magnesium alloys for die cast.

\section{Materials and Experimental Procedures}

The initial magnesium alloy AZ91D was in chip form, and its chemical compositions as analyzed with EPMA basically met the standard except small inadequacy of $\mathrm{Mn}$ element $(8.68 \% \mathrm{Al}, 0.73 \% \mathrm{Zn}$ and $0.09 \% \mathrm{Mn}){ }^{11)} \mathrm{In}$ addition to this fresh chip condition, two more treatments were performed in order to obtain different surface conditions on the chips. One was to have the chips receiving $300^{\circ} \mathrm{C}$ air environment for two hours, and the other was to immerse them into sea water for two days. The fresh metal chips were then pressed into a die to form a compact shape of $50 \mathrm{~mm}$ diameter and $50 \mathrm{~mm}$ length (Fig. 1), using a press machine of 100 tons capacity.

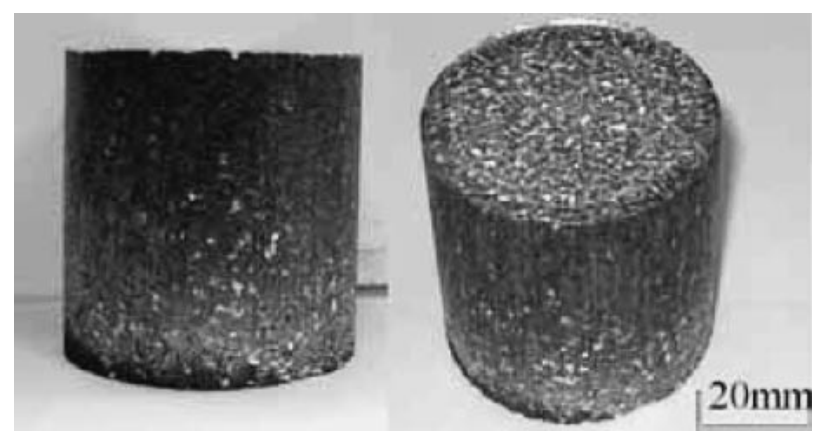

Fig. 1 The green compact consisting of fresh chips as formed with a 100 tons press machine.

The green density of the workpart after pressing is $1.6 \mathrm{~g} / \mathrm{cm}^{3}$ which is $88 \%$ of the fully condensed solid of $1.81 \mathrm{~g} / \mathrm{cm}^{3}$. This green compact was then sintered at $300^{\circ} \mathrm{C}$ for $4 \mathrm{~h}$. The final working step was to extrude the $50 \mathrm{~mm}$ diameter green compact into a $20 \mathrm{~mm}$ diameter bar at $350^{\circ} \mathrm{C}$. The other two conditioned chips followed similar route only that the final product shape is $10 \mathrm{~mm}$ thick plate. In this paper, most studies were centered on the extruded fresh chip material, which received homogenization at $415^{\circ} \mathrm{C}$ for $24 \mathrm{~h}$. Then solution and aging treatment was conducted for improving the strength, which was maintained at $415^{\circ} \mathrm{C}$ for $0.5 \mathrm{~h}$ followed by oil quenching, plus aging at $170^{\circ} \mathrm{C}$ for 1 to $200 \mathrm{~h}$. Referring to the ASTM E8M spec, standard tensile specimens of round shape were prepared to test the material's strengths and elongations at room temperature and initial strain rate of $1.31 \times 10^{-4} \mathrm{~s}^{-1}$ after the above prescribed processing. Microstructure analyses were carried out using optical, scanning electron microscope (SEM) and transmission electron microscope (TEM). All the micrographs were shot from the specimens showing the plane perpendicular to the extrusion direction.

\section{Results and Discussion}

3.1 Sintering ability of the extruded and microstructure of the homogenized

As mentioned, three different surface conditioned chips 
(a)

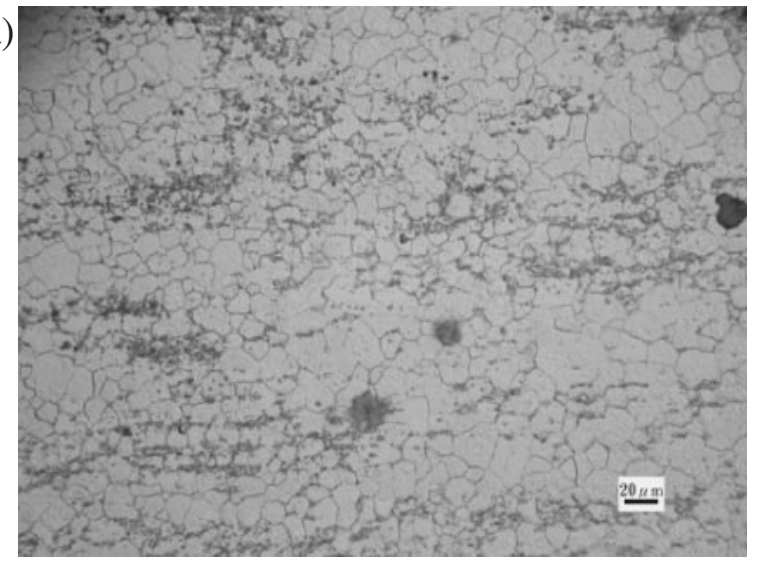

(c)

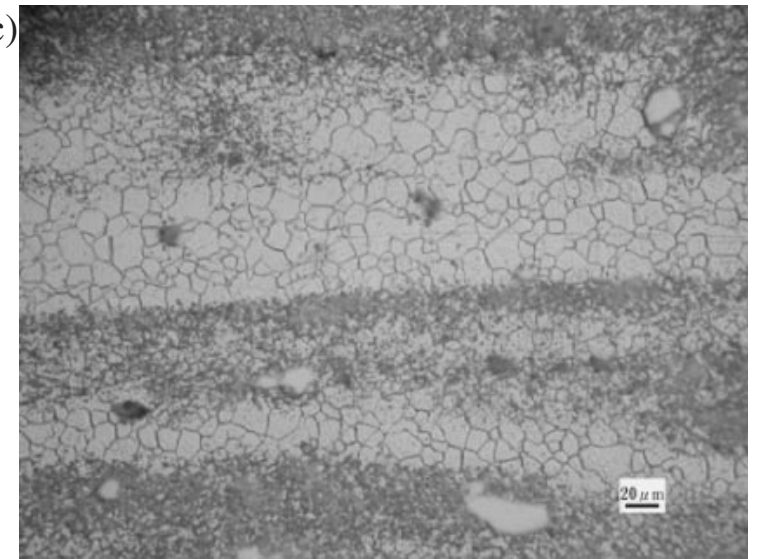

(b)

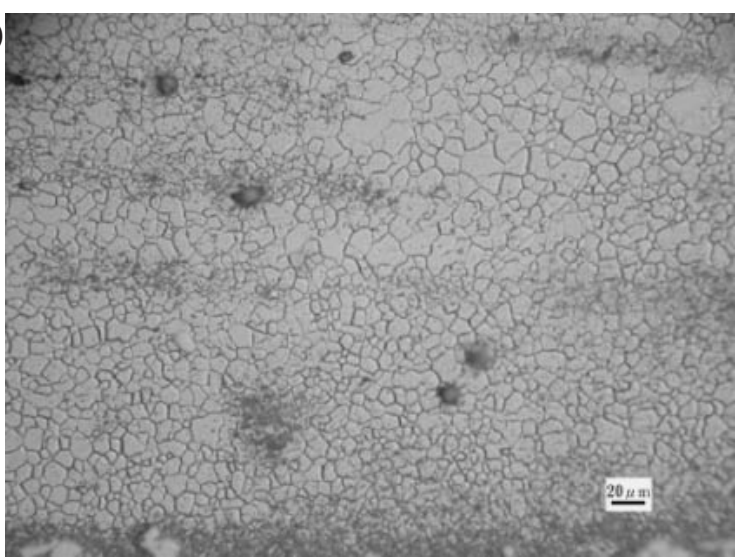

Fig. 2 Optical micrographs of the extruded specimens from: (a) fresh chips with average grain size of $10.2 \mu \mathrm{m}$ (max: $44.4 \mu \mathrm{m}, \mathrm{min}: 3 \mu \mathrm{m}$ ), (b) that having been oxidized for $2 \mathrm{~h}$ at $300^{\circ} \mathrm{C} ; 8.9 \mu \mathrm{m}$ (max: $35.6 \mu \mathrm{m}$, min: $1.5 \mu \mathrm{m}$ ), (c) that receiving 2-days sea-water corrosion treatment; $10.5 \mu \mathrm{m}$ (max: $35.6 \mu \mathrm{m}$, $\min : 3 \mu \mathrm{m}$ ).

were extruded. Two of them, fresh chip and that receiving high temperature oxidation sintered well. The third one which had been corroded in sea water for two days partially sintered. Their optical micrographs are presented in Fig. 2 showing a defect free granular structure, and the grain size is determined. The recycled from fresh chips has a strength of $289.5 \mathrm{MPa}$ associated with $6.9 \%$ elongation. The hot air oxidized one shows strength of $271 \mathrm{MPa}$ with $2.3 \%$ elongation. The second oxidized one shows a strength of $281 \mathrm{MPa}$ with $1 \%$ elongation. And the sea water treated one, which is over corroded, has strength of $231 \mathrm{MPa}$ and elongation of $1.7 \%$. Compare these figures with those from the die cast are $255 \pm 5 \mathrm{MPa}$ and $6.2 \pm 1.2 \%,{ }^{12)}$ solid state recycling is certainly feasible as the mechanical properties are no inferior. We also prepared extruded bulk AZ91D for a further comparison, which has $336 \mathrm{MPa}$ UTS of and $14.4 \%$ elongation. Obviously, the strengths and elongations of recycled are quite lower than their regular counterpart. There must be a mechanism accountable for this inadequacy, and some fundamental study needs to be done. Fine particles of size well below $3 \mu \mathrm{m}$ are dispersed in the matrix, and identified as $\mathrm{Mg}_{17} \mathrm{Al}_{12}$ by EPMA and SEM/EDS. The subsequent $415^{\circ} \mathrm{C} \times 24 \mathrm{~h}$ homogenization increased the grain size significantly to $23 \mu \mathrm{m}$ (ranging from 7 to 75 ), and dissolved most of prior particle phase developed in the extruded stage (Fig. 3).

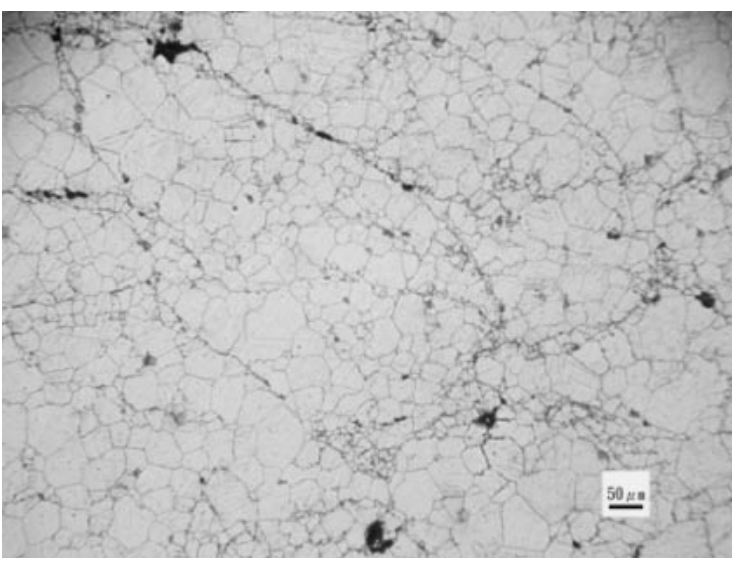

Fig. 3 Microstructure of the specimen from fresh chips after homogenization at $415^{\circ} \mathrm{C}, 24 \mathrm{~h}$.

\subsection{Eutectic-like lamellar structure developed after aging treatment}

It is well known that cast bulk AZ91D is aging hardenable, and this capability is also preserved in the recycled as exhibited by the tensile test data (Fig. 4). Solution treatment at $415^{\circ} \mathrm{C}$ for $0.5 \mathrm{~h}$ seemed to eliminate the extruded microstructure, and yield a solid solution phase (Fig. 5). The subsequent aging performed at $170^{\circ} \mathrm{C}$ for a short time, one 


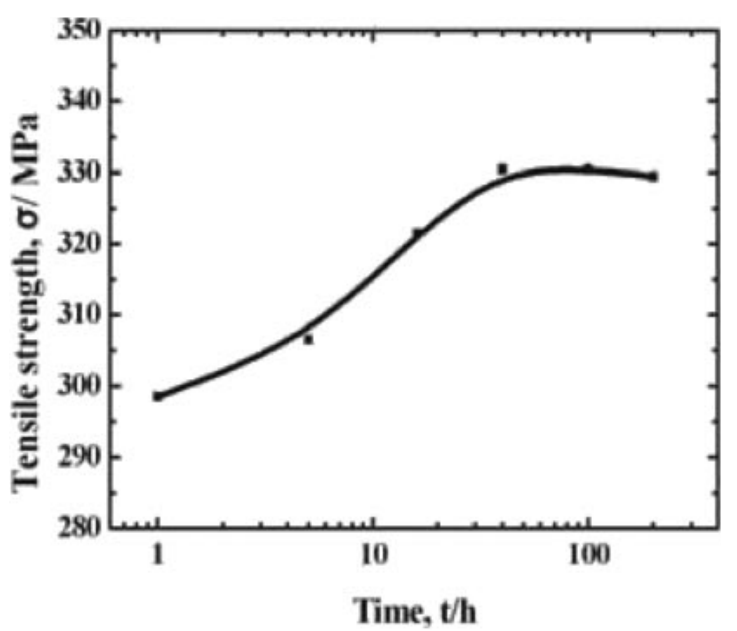

Fig. 4 Strength of the specimens from fresh chips as aged at $170^{\circ} \mathrm{C}$ for various hours.

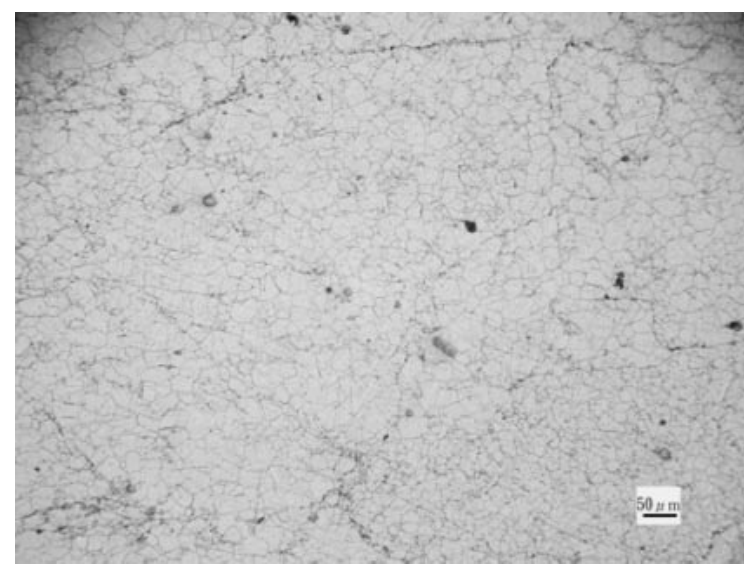

Fig. 5 Microstructure of the specimen from fresh chips after solution treatment at $415^{\circ} \mathrm{C}$ for $0.5 \mathrm{~h}$, oil quenched.

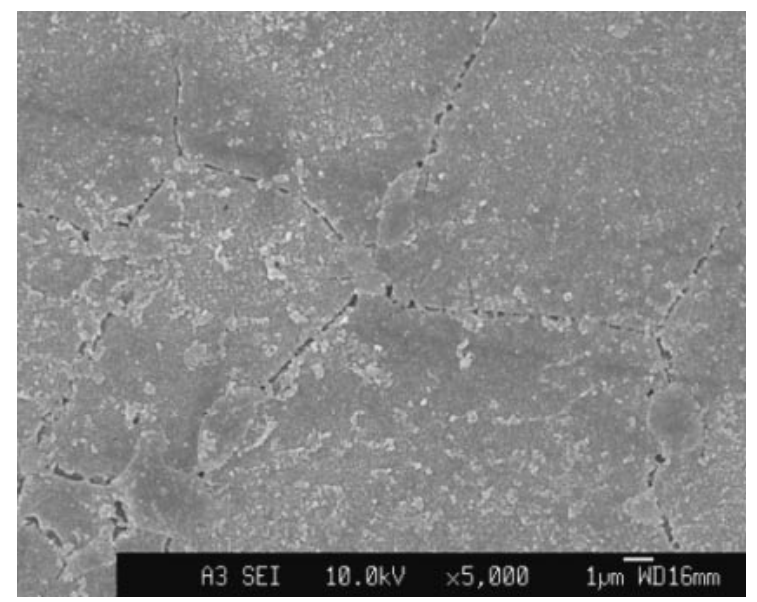

Fig. 6 Microstructure of the specimen from fresh chips after solution treatment plus $1 \mathrm{~h}$ aging at $170^{\circ} \mathrm{C}$.

hour, did not produce apparent microstructure variation (Fig. 6). As extending the time to $40 \mathrm{~h}$, obvious but unexpected change of microstructure occurred (Fig. 7). Under optical microscope of low magnification, a significant

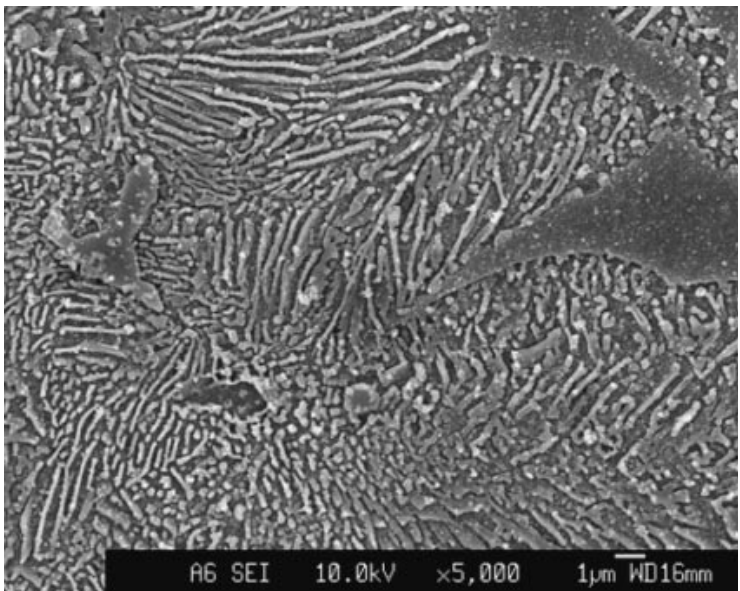

Fig. 7 Microstructure of the specimen from fresh chips after solution treatment plus $40 \mathrm{~h}$ aging at $170^{\circ} \mathrm{C}$.

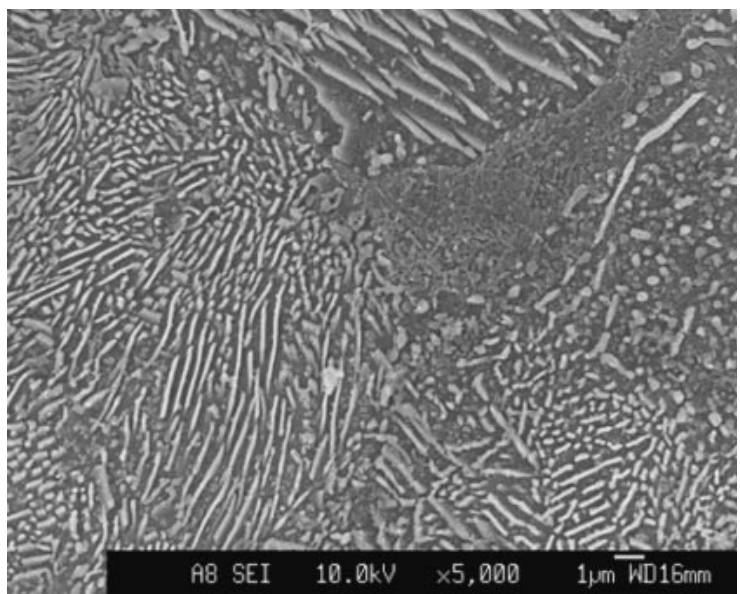

Fig. 8 Microstructure of the specimen from fresh chips after solution treatment plus $200 \mathrm{~h}$ aging at $170^{\circ} \mathrm{C}$.

portion of the matrix darkened seeming to have experienced some kind of phase transformation. The degree of transformation increased with the length of aging time as $200 \mathrm{~h}$ entailed more darkened area (Fig. 8). With the higher resolution of SEM, the transformed morphology is clear and exhibits lamellar structure, which is typical from eutectic reaction. It is of interest to know how the process of solution treatment followed by a long time aging, can lead to a seemingly eutectic structure.

\subsection{TEM analyses}

The previously analyzed extruded structure was further investigated by TEM, especially for identifying the particle phase (Fig. 9). Analyses by selected area diffraction pattern (SADP) and energy dispersive spectrometer (EDS) identified the particle as $\mathrm{Mg}_{17} \mathrm{Al}_{12}$ which commonly exists in AZ91. The bright field image showed this particle of size around $0.5 \mu \mathrm{m}$, and the matrix containing narrow and long stripes of $\sim 0.1 \mu \mathrm{m}$ width. It is noted the appearance of eutectic-like structure, mostly located adjacent to the $\beta$ particle, which may have connection with the lamellae formation in the following aging process. The micrograph of the specimen 
(a)

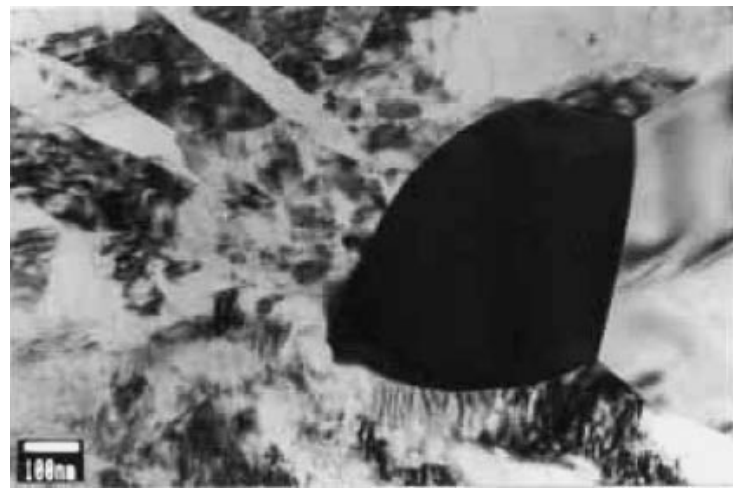

(b)

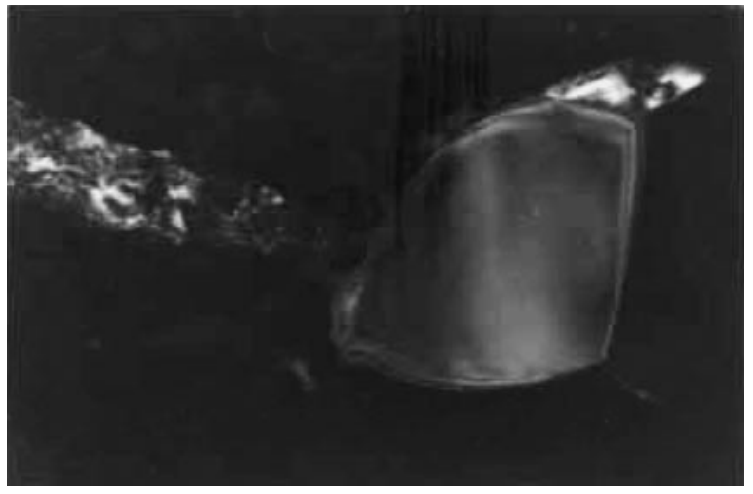

(c)

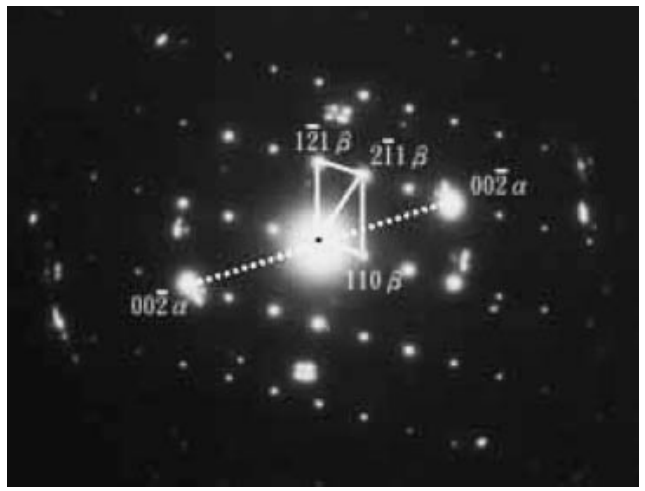

(d)

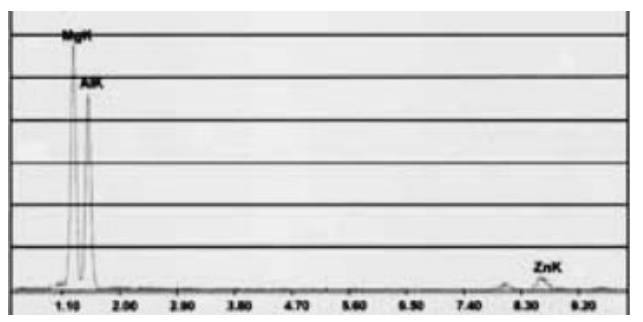

Fig. 9 TEM analyses of the extruded microstructure from fresh chips: (a) Bright field, (b) Dark field, (c) SADP identifying $\mathrm{Mg}_{17} \mathrm{Al}_{12}$ phases within magnesium matrix and (d) EDS on the particle.

(a)

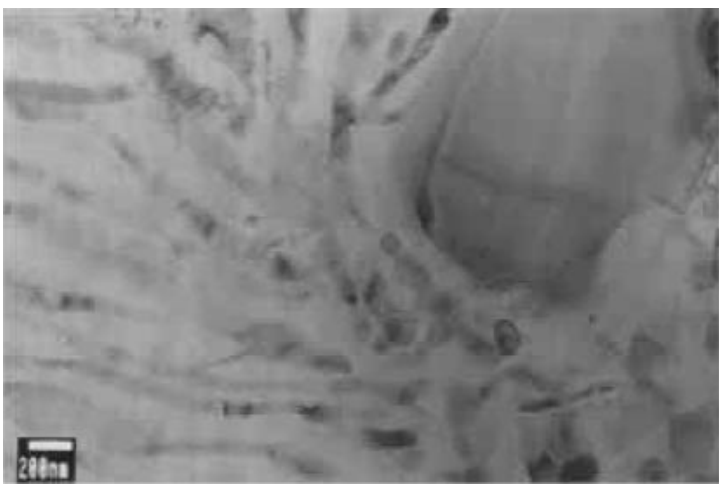

(c)

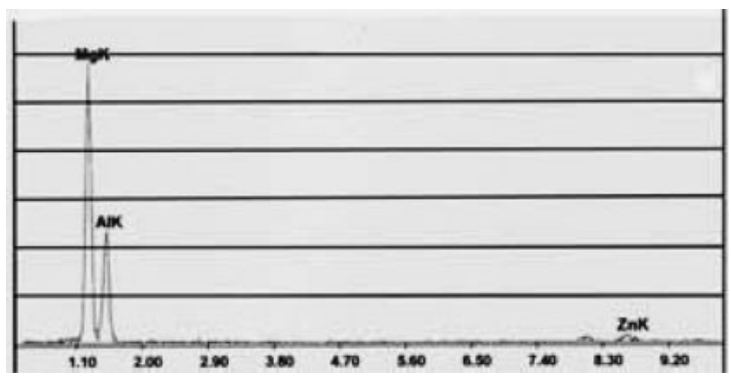

(b)

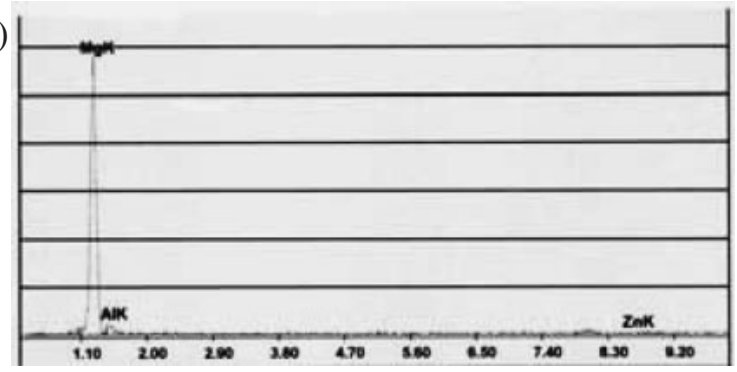

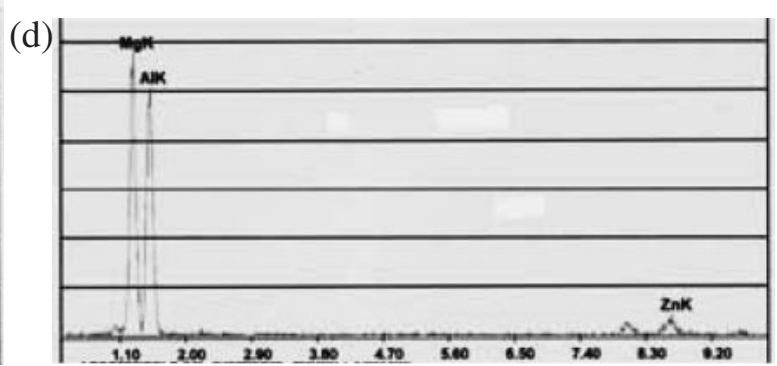

Fig. 10 TEM analyses of the microstructure from fresh chips subjected to aging for $40 \mathrm{~h}$ : (a) Bright field micrograph, (b) EDS on the matrix, (c) EDS on the lamella and (d) EDS on the particle.

aged for $40 \mathrm{~h}$ in Fig. 10 shows the widths of lamellae and their inter-spacing. EDS on these indicates the lamellar structure with $\mathrm{Mg}_{17} \mathrm{Al}_{12}$ distributed in the magnesium matrix. Also some $\mathrm{Mg}_{17} \mathrm{Al}_{12}$ particles in the extruded structure still remained even after aging treatment.

\section{Summary}

When even subjected to severe corrosion condition, this study proves the possibility of solid-state recycling of magnesium alloy scraps. The recycled AZ91D showed 
defect-free morphology and comparable strength and ductility as the original material. Also the strength of recycled AZ91D magnesium alloy can be improved by subsequent aging treatment. These positive results warrant further works with diversified source of scraps. Microstructures of the specimens after aging treatment is inferred as the isothermal transformation and deserve further researches.

\section{Acknowledgment}

This research is supported by National Science Council, Taiwan, under the contract No. NSC94-2622-E-259-001CC3.

\section{REFERENCES}

1) J. Y. Wang, W. P. Hong, P. C. Hsu, C. C. Hsu and S. Lee: Mater. Sci. Forum 419-422 (2003) 165-170.

2) Y. Kojima and S. Kamado: Mater. Sci. Forum 488-489 (2005) 9-16.
3) B. L. Mordike and K. U. Kainer: Magnesium Alloys and their Applications, (Present State of Recycling of Magnesium and its Alloys, C. Scharf, A. Ditze, 1998) pp. 685-690.

4) Y. Chino, M. Mabuchi, T. Hoshika, J. S. Lee, K. Shimojima, H. Hosokawa, Y. Yamada and H. Iwasaki: Mater. Sci. Forum 488-489 (2005) 567-570.

5) Y. Chino, R. Kishihara, K. Shimojima, C. Wen, H. Iwasaki and M. Mabuchi: Proc. of the 4th Pac. Rim Int. Conf. on Advanced Mater and processing, held from 11-14 Dec. (2001) 1291-1294.

6) K. Kondoh, T. Luangvaranunt and T. Aizawa: Keikinnzoku 51 (2001) 516-520 (in Japanese).

7) K. Kondoh, T. Luangvaranunt and T. Aizawa: Mater. Trans. 43 (2002) 322-325.

8) D. Lee, J. Lee and C. Lee: Keikinnzoku 45 (1995) 391-396 (in Japanese).

9) M. Inoue, T. Yamaguchi, R. Hirasawa and Y. Kojima: Proc. of the Asian Symposium on Ecotechnology-TOYAMA'94, Toyama, Japan 1 (1995) 129-134.

10) Tetsuo Aida, Norio Takatsuji, Kenji Matsuki, Shigeharu Kamado and Yo Kojima: J. JILM 54 (2004) 532-537.

11) Aerospace Structural Metals Handbook, Code 3402 (1992) 6.

12) S. Ando and H. Tonda: Mater. Sci. Forum 350-351 (2000) 43-48. 